\title{
Fine Mapping of Leaf Rust Resistance Gene LrZH84 Using Expressed Sequence Tag and Sequence-Tagged Site Markers, and Allelism with Other Genes on Wheat Chromosome 1B
}

\author{
Yue Zhou, Xianchun Xia, Zhonghu He, Xing Li, Zaifeng Li, and Daqun Liu
}

First author: Department of Plant Pathology, College of Plant Protection, Agricultural University of Hebei, Biological Control Center for Plant Diseases and Plant Pests of Hebei, 289 Lingyusi Street, Baoding 071001, Hebei, China; second author: Institute of Crop Science, National Wheat Improvement Center, Chinese Academy of Agricultural Sciences, 12 Zhongguancun South Street, Beijing 100081, China; third author: Institute of Crop Science, National Wheat Improvement Center, Chinese Academy of Agricultural Sciences and CIMMYT China Office, 12 Zhongguancun South Street, Beijing 100081, China; and fourth, fifth, and sixth authors: Department of Plant Pathology, College of Plant Protection, Agricultural University of Hebei, Biological Control Center for Plant Diseases and Plant Pests of Hebei, 289 Lingyusi Street, Baoding 071001, Hebei, China.

Accepted for publication 28 September 2012.

\begin{abstract}
Zhou, Y., Xia, X., He, Z., Li, X., Li, Z., and Liu, D. 2013. Fine mapping of leaf rust resistance gene $L r Z H 84$ using expressed sequence tag and sequence-tagged site markers, and allelism with other genes on wheat chromosome 1B. Phytopathology 103:169-174.

Zhou $8425 \mathrm{~B}$, possessing the leaf rust resistance gene $\mathrm{LrZH} 84$, is an elite wheat (Triticum aestivum) parental line in the Yellow-Huai Valley region of China. In the present study, 2,086 $\mathrm{F}_{2}$ plants derived from Zhou

used to screen the two parents and resistant and susceptible bulks; those polymorphic were used to analyze the entire $\mathrm{F}_{2}$ population. Three EST markers (BF474863, BE497107, and CD373538) were closely linked to LrZH84, with genetic distances of $0.7,0.7$, and $1.7 \mathrm{cM}$, respectively. STS marker $H b s f-1$ was developed from the sequences of polymerase chain reaction fragments amplified from EST marker BF474863. LrZH84 was $8.19 \mathrm{cM}$ proximal to $L r 44$, but may be allelic to $L r X i$ and $L r G 98$ although they showed different reactions with some Puccinia triticina pathotypes.
\end{abstract} 8425B/Chinese Spring were used for fine mapping of LrZH84 with expressed sequence tag (EST) and sequence-tagged site (STS) markers. Seventy inter-simple sequence repeat EST and STS markers on 1BL were
Additional keywords: allelism test, genetic mapping, molecular markers.
Leaf rust, caused by Puccinia triticina, is an important wheat disease in many countries worldwide. It is adapted to a wide range of environments, occurs wherever wheat is grown, and can cause significant yield losses. During the past decade, leaf rust has periodically caused destructive yield losses in major Chinese wheat regions, particularly in northern China and the Yellow and Huai valleys (33). Planting resistant wheat cultivars is an efficient, economic, and environmentally safe means to reduce the damage caused by leaf rust.

Much effort has been made in searching for resistance to leaf rust in wheat. To date, about 68 resistance genes have been catalogued $(12,18)$. Most are race-specific. It is, therefore, very important to identify and use new leaf rust resistance genes in breeding programs.

Molecular markers, including random amplification of polymorphic DNA, restriction fragment length polymorphism, simple sequence repeat (SSR), amplified fragment length polymorphism, and expressed sequence tag (EST), are useful tools for genetic mapping $(1,9,20,27,28)$. EST, short subsequences of a transcribed cDNA sequence, can be used to identify gene transcripts, and are instrumental in gene discovery and gene sequence determination (1). The identification of ESTs has proceeded rapidly in the Triticeae, and approximately 1.6 million are available in public databases (www.ncbi.nlm.nih.gov). Closely linked EST markers

Corresponding authors: Z. Li; E-mail address: 1zf7551@yahoo.com.cn D. Liu; E-mail address: 1dq@hebau.edu.cn

http://dx.doi.org/10.1094/PHYTO-08-12-0186-R

(c) 2013 The American Phytopathological Society provide a useful tool for pyramiding leaf rust resistance genes by marker-assisted selection in breeding programs.

The Chinese wheat line Zhou 8425B developed in 1984 is still resistant to leaf rust, stripe rust, and powdery mildew under field conditions in China (33). At least 38 cultivars developed from Zhou 8425B have been grown on an accumulated area of over 10 million hectares (30). Previously, we identified the dominant resistance gene $\mathrm{LrZH84}$ in Zhou 8425B. It was linked to SSR markers Xgwm582 and Xbarc8 with genetic distances of 3.9 and $5.2 \mathrm{cM}$, respectively (33). Six wheat leaf rust resistance genes ( $L r 46, L r 33, L r 44, L r Z H 84, L r G 98$, and $L r X i$ ) have been reported on $1 \mathrm{~B}(4,8,15,33)$. $L r 46$ is an adult-plant resistance gene located in the terminal region of chromosome $1 \mathrm{BL}(23,25)$, whereas LrZH84 is a seedling resistance gene located in the proximity of the centromere. In previous seedling tests, races PKSS, PHSL, PKJS, and PHSN, virulent on Zhou $8425 \mathrm{~B}$ were avirulent to $\mathrm{Lr} 44$, indicating that $\mathrm{LrZH84}$ is different from $\mathrm{Lr} 44$ (33). Lr44 derived from a spelt wheat accession was located on chromosome 1BL, $5.4 \mathrm{cM}$ from $\operatorname{Lr33}$ (8). The reaction types of $\operatorname{LrG98}$ and $L r X i$ to some pathotypes are different from those of $L r Z H 84$, and their possible allelism with $\operatorname{LrZH84}$ remains unclear $(4,15)$. $\operatorname{Lr} 33$ was mapped on $1 \mathrm{BL} 2.6 \mathrm{cM}$ from $L r 26$, representing the $1 \mathrm{~B}$ centromere region (7). This places $L r 33$ locus in the same vicinity as LrZH84. Lr33 is not effective against all Chinese races, and LrZH84 and Lr33 may be different, but closely linked genes. Thus, four leaf resistance genes ( $\mathrm{Lr} 44, \mathrm{Lr} 33, \mathrm{LrG} 98$, and $\mathrm{LrXi}$ ) are very closely linked or allelic to $\mathrm{LrZH} 84$.

The objectives of this study were to fine map LrZH84 in a large $\mathrm{F}_{2}$ population from Zhou $8425 \mathrm{~B} /$ Chinese Spring using EST and sequence-tagged site (STS) markers as a prelude to its cloning 
and possible use in more precise marker assisted selection, and to test the allelism of $\mathrm{LrZH} 84$ with $\mathrm{Lr} 44, \mathrm{LrG} 98$, and $\mathrm{LrXi}$. Because all $P$. triticina pathotypes tested were virulent to $L r 33$, an allelism test between LrZH84 and Lr33 was not performed. Zhoumai 11, developed from Zhou $8425 \mathrm{~B} /$ Yumai 17 , is resistant to more races than Zhou 8425B. An $F_{2}$ population from Zhoumai 11/Chinese Spring was tested to determine the genetic basis of leaf rust resistance in Zhoumai 11 and further confirm the relationship between the resistance gene in Zhoumai 11 and LrZH84.

\section{MATERIALS AND METHODS}

Wheat germplasm and $\boldsymbol{P}$. triticina pathotypes. An $\mathrm{F}_{2}$ population with 2,086 plants, developed from Zhou 8425B/Chinese Spring, was used for mapping $\mathrm{LrZH84}$. Forty near-isogenic lines (NILs) with different leaf rust resistance genes, and 38 Chinese wheat cultivars and advanced lines derived from Zhou 8425B were used to validate the STS marker (Table 1). A total of $606 \mathrm{~F}_{2}$ plants from RL6147 ( $\mathrm{Lr} 44) / Z$ hou 8425B, $837 \mathrm{~F}_{2}$ plants from Xinong 1163-4/Zhou 8425B, and $838 \mathrm{~F}_{2}$ plants from Guizhou 9818/Zhou 8425B were employed to test the allelism of $\mathrm{Lr} 44, \mathrm{LrXi}$, and $L r G 98$ with $L r Z H 84$. To investigate the relationship between LrZH84 and the resistance genes in Zhoumai 11 and Xinong $1163-4,430 \mathrm{~F}_{2}$ plants from Zhoumai 11/Chinese Spring and 232 $\mathrm{F}_{2}$ plants from Xinong 1163-4/Thatcher were used for genetic analysis. The three $P$. triticina pathotypes PHTS, THTT, and
FHTT used in the allelism tests and genetic analysis are maintained at the Biological Control Centre for Plant Diseases and Plant Pests of Hebei, Hebei Agricultural University, Baoding.

Evaluation of seedling responses in the greenhouse. Zhou $8425 \mathrm{~B}$, Chinese Spring, and the $\mathrm{F}_{2}$ population were inoculated with Chinese $P$. triticina pathotype THTT. Pathotype PHTS was used to test the allelism of $\mathrm{Lr} 44$ and $L r Z H 84$, and THTT was used to test the allelism of $L r X i$ and $L r G 98$ with $L r Z H 84 . \mathrm{F}_{2}$ populations from Zhoumai 11/Chinese Spring was inoculated separately with THTT and FHTT, and the $\mathrm{F}_{2}$ population from Xinong 11634/Thatcher was inoculated with FHTT. In the test, PHTS was avirulent on RL6147 ( $\mathrm{rr44}$ ) and Zhou 8425B; THTT was virulent on Chinese Spring, and avirulent on Xinong 1163-4, Guizhou 9818, Zhoumai 11, and Zhou 8425B; FHTT was virulent on Zhou 8425B, RL6078 (Lr26), Chinese Spring, and Thatcher, and avirulent on Xinong 1163-4, Guizhou 98-18, and Zhoumai 11 (Table 2).

Seedlings were grown in a growth chamber programmed with $12 \mathrm{~h}$ light $/ 12 \mathrm{~h}$ darkness at 18 to $22^{\circ} \mathrm{C}$ with $50 \%$ relative humidity (RH). When the first leaf was fully expanded, the seedlings were sprayed by water with little Tween $20(0.03 \%)$ and inoculations were performed by brushing urediniospores from fully infected susceptible genotypes onto the seedlings to be tested. Inoculated seedlings were placed in plastic-covered cages and incubated at $15^{\circ} \mathrm{C}$ and $100 \% \mathrm{RH}$ for $24 \mathrm{~h}$. They were then transferred to a growth chamber programmed with $12 \mathrm{~h}$ light/12 $\mathrm{h}$ darkness at 18 to $22^{\circ} \mathrm{C}$ with $70 \% \mathrm{RH}$. Infection types (IT) were scored 10 to

TABLE 1 . Thirty-eight Chinese wheat cultivars and advanced lines used to validate the sequence-tagged site marker $H b s f-1$

\begin{tabular}{|c|c|c|c|c|}
\hline Line number & Cultivar or line & Pedigree & $H b s f-1^{\text {a }}$ & Infection type with THTT \\
\hline 1 & Zhoumai 11 & Zhou 8425B/Yumai 17 & + & 2 \\
\hline 2 & Zhoumai 17 & Aizao 781/Zhou 8425B//Zhoumai 9 & + & 1 \\
\hline 3 & Zhou 99343 & Zhou 8425B/Zhoumai 9 & + & $; 1$ \\
\hline 4 & Zhou 9926 & Zhoumai 11 (Zhou 8425B/Yumai 17)//Shan 225 & + & 1 \\
\hline 5 & Luomai 21 & Zhoumai 13 (Zhou 8425B//Zhoumai 9)/Luomai 1 & + & 2 \\
\hline 6 & Yuzhan 10 & Yanzhan 1/Zhoumai 16(Zhoumai 9/Zhou 8425B) & + & 2 \\
\hline 7 & Luo 9908 & Zhoumai 13 (Zhou 8425B/Zhoumai 9)/Yumai 54 & + & 1 \\
\hline 8 & Meng 0318 & Zhoumai 13 (Zhou 8425B/Zhoumai 9)/Yumai 65//Xuzhou 21 & + & 2 \\
\hline 9 & Zhengyumai 033 & Zhoumai 13 (Zhou 8425B/Zhoumai 9)/Zhongyu 5 & + & 1 \\
\hline 10 & Huapei 212 & Zhongyu 5/Zhoumai 11(Zhou 8425B/Yumai 17) & + & 2 \\
\hline 11 & Xumai 270 & Zhou 91098 (Yumai18/Zhou 8425B)/Xuzhou 25 & + & 1 \\
\hline 12 & Pu 96105 & Zhou 8425B/Heng 904041 & - & 1 \\
\hline 13 & 04zhong 36 & Yumai 54/Zhoumai 11 (Zhou 8425B/Yumai 17) & + & 2 \\
\hline 14 & Yuanyu 3 & Yumai 54/Zhoumai 11 (Zhou 8425B Yumai 17) & - & 3 \\
\hline 15 & Wankang 18 & Zhoumai 11 (Zhou 8425B/Yumai 17)/Yumai 18 & + & 2 \\
\hline 16 & Huanong 139 & Zhoumai 13 (Zhou 8425B/Zhoumai 9)/Yumai 49 & + & ;1 \\
\hline 17 & Fuzhi 1 & XianyangchaodasuiLK/Zhoumai 13 (Zhou 8425B/Zhoumai 9) & + & 1 \\
\hline 18 & Tianhe 0519 & Yumai 54/Zhoumai 13 (Zhou 8425B/Zhoumai 9) & + & 1 \\
\hline 19 & Hongzhan 9908 & Pu 87542/Zhoumai 13 (Zhou 8425B/Zhoumai 9)//Yumai 34 & + & 1 \\
\hline 20 & Zhengnong 21 & Zhoumai 16 (Zhoumai 9/Zhou 8425B)/Zhengnong 99077 & + & 2 \\
\hline 21 & 05zhong 37 & Zhoumai 11 (Zhou 8425B/Yumai 17)/Lu 95(5)161 & + & 2 \\
\hline 22 & Ruixing 983 & Zhoumai 13 (Zhou 8425B/Zhoumai 9)/Yumai 54//Yumai 49 & - & 4 \\
\hline 23 & Huaimai 0566 & Zhoumai 13 (Zhou 8425B/Zhoumai 9)/Yumai 49 & + & 2 \\
\hline 24 & Luo 6112 & Zhoumai 13 (Zhou 8425B/Zhoumai 9)/Yumai 54//Zhoumai 13 & + & 1 \\
\hline 25 & Hemai 026 & Mutated line in Zhoumai 13 (Zhou 8425B/Zhoumai 9) & + & 1 \\
\hline 26 & Luomai 22 & Zhoumai 13 (Zhou 8425B/Zhoumai 9)/Yumai 49 & + & 1 \\
\hline 27 & Zhongyu 740 & Zhoumai 11 (Zhou 8425B/Yumai 17)/Zhengmai 98 & + & 1 \\
\hline 28 & Shi 06-6090 & Shan 3025/Zhoumai 11 (Zhou 8425B/Yumai 17) & + & 1 \\
\hline 29 & Xuke 1018 & Zhoumai 13 (Zhou 8425B/Zhoumai 9)/92R139 & + & 1 \\
\hline 30 & Zhengyumai 9988 & Yumai 2/Zhoumai 13 (Zhou 8425B/Zhoumai 9) & + & 2 \\
\hline 31 & Zhongxin 78 & Zhoumai 13 (Zhou 8425B/Zhoumai 9)/Luomai 4 & + & 2 \\
\hline 32 & Yunong 209 & Zhoumai 15 (Su8802//Zhou 8425B//Neixiang182)//8329/Aikang 20 & + & 2 \\
\hline 33 & Pingan 8 & Xiang 8820/Zhoumai 13 (Zhou 8425B/Zhoumai 9) & + & 2 \\
\hline 34 & Tunmai 9 & Xinong 2611/Zhoumai 13 (Zhou 8425B/Zhoumai 9) & - & 3 \\
\hline 35 & Luo 0313 & Zhoumai 16 (Zhoumai 9/Zhou 8425B)/Luomai 4 & - & 4 \\
\hline 36 & Xumai 7074 & Zhou 93S/Zhoumai 16 (Zhoumai 9/Zhou 8425B) & - & 3 \\
\hline 37 & Xinong 837 & Xinong 953/Zhoumai 16(Zhoumai 9/Zhou 8425B) & - & 3 \\
\hline 38 & Jinmai 8 & Jimai 5418/Zhoumai 11 (Zhou 8425B/Yumai 17)//Yuzhan 1 & + & 2 \\
\hline 39 & Zhou $8425 B^{b}$ & Guangmai 74/Lianfeng 1//Predgornayi 2/3/Annong 7959 & + & 2 \\
\hline 40 & Chinese Spring ${ }^{\mathrm{c}}$ & Landrace & - & 4 \\
\hline
\end{tabular}

a + , present; -, absent.

b Resistant check.

c Susceptible check. 
14 days after inoculation according to the Stakman scale as modified by Roelfs et al. (22). The plants with IT 0 to $2+$ were considered to be resistant and those with IT of 3 to 4 were susceptible.

DNA extraction and bulk preparation. Genomic DNA was extracted from seedlings of $\mathrm{F}_{2}$ plants using the CTAB protocol (24). DNA was quantified with a UV spectrophotometer, and diluted to a final concentration of $30 \mathrm{ng} / \mu \mathrm{l}$ prior to further analysis. Bulked segregant analysis (19) was performed to identify molecular markers putatively linked to the leaf rust resistance gene. Genomic DNA from 20 resistant and 20 susceptible $F_{2}$ plants, respectively, were mixed in equal amounts to form resistant and susceptible bulks. DNA samples of the two parents and bulks were screened for polymorphism with EST markers.

EST analyses. Seventy EST markers (http://www.ncbi.nlm. nih.gov/dbEST/index.html) on wheat chromosome 1BL were used to screen the two parents and resistant and susceptible bulks. Polymorphic EST markers were used to analyze the entire $\mathrm{F}_{2}$ population (Table 3). Polymerase chain reactions (PCR) were performed in volumes of $20 \mu \mathrm{l}$ containing $0.5 \mathrm{U}$ of Taq DNA polymerase (Zexing Biotechnology Co. Ltd., Beijing, China), $2 \mu \mathrm{l}$ of buffer ( $50 \mathrm{mM} \mathrm{KCl}, 10 \mathrm{mM}$ Tris- $\mathrm{HCl}, 1.5 \mathrm{mM} \mathrm{MgCl}_{2}, \mathrm{pH} 8.3$ ), $200 \mu \mathrm{M}$ of each dNTP, 4.8 pmol of each primer, and $120 \mathrm{ng}$ of template DNA. PCR conditions were an initial denaturation at $94^{\circ} \mathrm{C}$ for $5 \mathrm{~min}$, followed by 40 cycles of $94^{\circ} \mathrm{C}$ for $1 \mathrm{~min}, 53$ to $61^{\circ} \mathrm{C}$ (depending on primer pair) for $1 \mathrm{~min}, 72^{\circ} \mathrm{C}$ for $1 \mathrm{~min}$, and a final extension at $72^{\circ} \mathrm{C}$ for $10 \mathrm{~min}$. PCR products $(5 \mu \mathrm{l})$ were mixed with $1 \mu \mathrm{l}$ of formamide loading buffer $(98 \%$ formamide, $10 \mathrm{mM}$ EDTA, $0.25 \%$ bromo-phenol blue, $0.25 \%$ xylene cynol, $\mathrm{pH} 8.0$ ), and then loaded on $6 \%$ denaturing polyacrylamide gels, and run at $80 \mathrm{~W}$ for approximately $3 \mathrm{~h}$ and visualized by silver staining (2).

Identification of 1BL.1RS translocation. The 1BL.1RS translocation is present in Zhou 8425B and is linked to LrZH84 (33). To determine the relationship between the $1 \mathrm{BL} .1 \mathrm{RS}$ translocation and $L r Z H 84$, DNA from $\mathrm{F}_{2}$ plants were assayed with a genespecific marker for $\omega$-secalin, generating a 1,076-bp fragment in genotypes with 1BL.1RS (3), and a marker for Glu-B3 producing a 636-bp fragment in genotypes without 1BL.1RS (5), following the procedure described by Zhang et al. (32) with minor modifications.

TABLE 2. Seedling infection types of some lines tested with pathotypes PHTS, THTT, and FHTT

\begin{tabular}{lccc}
\hline & \multicolumn{3}{c}{ Pathotype } \\
\cline { 2 - 4 } Line & PHTS & THTT & FHTT \\
\hline Zhou 8425B & 2 & 2 & 4 \\
RL6147 (Lr44) & 1 & & \\
RL6078 (Lr26) & 4 & 4 & 4 \\
Guizhou 98-18 & & $; 1$ & 1 \\
Xinong 1163-4 & & 3 & 1 \\
Zhoumai 11 & & 1 & 4 \\
Chinese Spring & 4 & 4 & 4 \\
Thatcher & 4 & 4 &
\end{tabular}

TABLE 3. Primers of three expressed sequence tag and one sequence-tagged site markers closely linked to $\mathrm{LrZH} 84$ and sizes of polymerase chain reaction fragments amplified

\begin{tabular}{llc}
\hline Marker name & \multicolumn{1}{c}{ Primer sequence $\left(5^{\prime}-3^{\prime}\right)$} & Size $(\mathrm{bp})$ \\
\hline BF474863 & TTATTCCTTCAACGGCCAAC & 1,006 \\
& AATGCACCGCAAAAGGATAG & \\
BE497107 & GCTGTCACGAGCGCATATTA & 409 \\
& TCTTTGGGATCTCCTGTGCT & 750 \\
CD373538 & GTCACTGACCTCCGGATCAT & \\
& CGGGTCGATGAGTATGGACT & 1,006 \\
& GTCTGCAAACTTGAAGGAAG & \\
& GCAGATTTCAGTTCATCCTC & \\
\hline
\end{tabular}

Cloning PCR fragments amplified from the EST markers. Closely linked EST markers were used to develop STS markers. The isolation of PCR fragments followed the method described by $\mathrm{Xu}$ et al. (29). Briefly, the PCR products from the EST markers were excised from dried gels. The spliced gel containing the DNA was transferred to a PCR tube, and twice eluted with $200 \mu \mathrm{l}$ of $1 \times$ TE buffer ( $\mathrm{pH}$ 8.0) for $30 \mathrm{~min}$, and once with $200 \mu \mathrm{l}$ of $\mathrm{ddH}_{2} \mathrm{O}$ for $30 \mathrm{~min}$. The gel was then soaked in $50 \mu \mathrm{l}$ of $\mathrm{ddH}_{2} \mathrm{O}$ and kept in a PCR thermocycler at $95^{\circ} \mathrm{C}$ for $10 \mathrm{~min}$ to release the DNA from the gel. After the gel debris was spun down by centrifuging at 3,000 rpm for $10 \mathrm{~min}$, the supernatant was used as template DNA for PCR amplification, using the same EST primers and PCR conditions.

Development of STS markers. The STS markers (Table 3, Fig. 1) were designed based on the sequences amplified with EST markers that were closely linked to LrZH84, using the software Premier Primer 5 (http://www.premierbiosoft.com). All EST and STS primers were synthesized by Shanghai Sangon Biological Engineering Technology \& Services Co., Ltd. (http://www. sangon.com/). The STS markers were tested for polymorphisms between the resistant and susceptible bulks as well as the parents. All 2,086 $\mathrm{F}_{2}$ plants of the mapping population were genotyped using the closely linked EST markers and the corresponding STS markers.

Statistical analysis. Chi square $\left(\chi^{2}\right)$ tests were used to evaluate the goodness of fit of observed and expected segregation ratios in

1 TTATTCCTTCAACGGCCAACTATCTGAATTTGTCTAAGATCAACCTTAATTTGTCTGCAA

61 ACTTGAAGGAAGTAGATTTGAAGCGCTCCAATCTTTACAATTTAAATTTGAGGTAATGCT

121 AatgTTAaTTTTTGTACTGTCCTAAGTTTGTCTTTTCAATATCTTTTGCTCTTACACTTT

181 GTACTATTCTACTTGCTTTTTTTTGCAGCAATTGTAACTCACTGGAGATTCTGAAGCTTG

241 ATTGCCCAAGATTGGCTAACCTCCAACTTTTGGTACTGTTCTTAATGCAACTCTCACCTG

301 AaCCCATTGTGAGCATGCATGATCTCTTAGTGTATAGGAAATTCAGGGATAAATTTAATG

361 CTGCTTCTGTTGATTATATTGATGGTGTTTGTTCTAATTCTTGAAAGCATGATTATACCA

421 AGTTATCTGTTATTCTTCATTTTTACTGATTCTTTTCGATGATCGCCTTTTAGCCTTTAT

481 GTTGTAagGTGTAAatgGTTTTACTGTTAaATTCAGAGTATGAgTTTGCAGTAACAAAAA

541 AAGCATCTAATTTATCTACCTTTTACAATAATTAACAGACCTGTAGCAACTATCCTCTGG

601 TGACATGAATGAAGAGGGATTGATACTTTTCTACACTTGCTAATTCCTTACAGCTGATGC

661 TATCATTATTAGTCATCTTACCCAGGATGTGAATGTATCTACAACTTAAAAGTAGCCTTT

721 ATGTATGTTGTATCTCAAACTGTGCTAAGTAATGATTGACCTCTCCTTTCTTCCTCGGCC

781 AAATACTTAAAATCTGTAAATGGGCCTCGTAGGCTTGGACGAGCTTCTGTCTAAAGAAAC

841 TATTTATATGGCGCAAACTTTGAATATTGATAATGGTAACAGATAGGCTAAACATTCATG

901 TATGTGCTTCATCTAGTATTCTTACATATACTTTATTCTTCCAATAGGCATGCACAATGT

961 TGCAAGAGGATGAACTGAAATCTGCACTATCCTTTTGCGGTGCATT

Fig. 1. DNA sequence of polymerase chain reaction fragment amplified with the expressed sequence tag marker BF474863. The primer positions of sequence-tagged site marker $H b s f-1$ are underlined. 
$\mathrm{F}_{2}$ populations. Linkage analysis was performed with the software Mapmaker 3.0b (17). The Kosambi mapping function was used to calculate the map distance, and a LOD threshold of 3.0 was employed for declaration of linkage.

\section{RESULTS}

Inheritance of leaf rust resistance in Zhou 8425B. Zhou 8425B seedlings were resistant to pathotype THTT (IT 2), whereas Chinese Spring was susceptible (IT 4). The $\mathrm{F}_{2}$ population segregated 1,561 plants with IT 0;-2 (resistant) and 525 plants with IT 3 to 4 (susceptible), indicative of a single dominant gene for resistance $\left(\chi_{3: 1}^{2}=0.031,1 \mathrm{df}, P>0.75\right)$.

Linkage analysis and genetic map. Of the 70 EST markers, BF474863, BE497107, and CD373538 (Table 3) co-segregated with resistance in a population comprising 50 resistant (IT 0;) and 50 susceptible (IT 4) $\mathrm{F}_{2}$ plants. The entire $\mathrm{F}_{2}$ population was then assayed (Fig. 2). The two closely linked markers $\omega$-secalin/Glu$B 3$ and $X g w m 582-1 B$ (33) were also used to assay the entire $\mathrm{F}_{2}$ population. The resistance gene $\mathrm{LrZH} 84$ was closely linked to the five markers with genetic distances ranging from 0.7 to $4.4 \mathrm{cM}$. The two closest linked EST loci flanking the resistance gene were $B E 497107-1 B$ and BF474863-1B, both with a genetic distance of $0.7 \mathrm{cM}$.

Development of STS markers. Based on the sequences of PCR fragments amplified with EST marker BF474863, an STS marker, $H b s f-1$, was designed. It generated a polymorphic band with an expected size of 1,006 bp in the resistant parent and resistant bulk (Table 3, Fig. 2). DNA alignments showed that the sequences of PCR products generated by $H b s f-1$ were consistent with those produced from the corresponding EST marker. When $H b s f-1$ was used to genotype the $\mathrm{F}_{2}$ population, the results were identical with those obtained with the corresponding EST marker BF474863 (Fig. 3).

Validation of the STS marker. STS marker $H b s f-1$ was tested on 40 Thatcher NILs and genetic stocks with different resistance genes, and a 1,006-kb PCR fragment was produced only in line RL6078 (Lr26). Because that Lr26 and LrZH84 are both present in the Zhou $8425 \mathrm{~B}$ and their loci are very closely linked (33), the STS marker also can be used to detect Lr26 in these lines. This result indicated that the STS marker could also be present in lines without LrZH84. The STS marker was tested on 38 cultivars and lines were derived from Zhou 8425B (Table 1). The STS marker was detected in 31 resistant lines, but was not present in six susceptible lines. Resistant line Pu 96105 (entry 12) did not have the specific band for $\mathrm{LrZH84}$, indicating that the line may carry a different gene for resistance to THTT or it could be a recombinant
(Table 1). These results indicated that the STS marker Hbsf-1 is effective in detecting $\mathrm{LrZH} 84$ in lines derived from Zhou 8425B.

Allelism of $\mathbf{L r Z H 8 4}$ and $\mathbf{L r 4 4}$. To test the allelism of $L r 44$ and LrZH84, pathotype PHTS was used to inoculate $606 \mathrm{~F}_{2}$ plants from Zhou 8425B/RL6147 ( $L r 44)$ and the two parents. The results showed that RL6147 ( $L r 44)$ and Zhou 8425B was resistant (IT 1 or 2), and the $F_{2}$ population segregated with 605 resistant plants (IT 0 to 2) and 1 susceptible plant (IT 4), indicative of close linkage between $\mathrm{Lr} 44$ and $\mathrm{LrZH} 84$, and the genetic distance between $\mathrm{Lr} 44$ and $\mathrm{LrZH} 84$ was estimated to be $8.19 \pm 2.4 \mathrm{cM}$. The corresponding $\mathrm{F}_{3}$ line from the $\mathrm{F}_{2}$ plant scored as susceptible was homozygous susceptible, which further confirmed the results from $\mathrm{F}_{2}$ population.

Allelism of $\mathbf{L r G 9 8}$ and $\mathbf{L r X i}$ with $\mathbf{L r Z H 8 4}$. All $837 \mathrm{~F}_{2}$ plants from Xinong 1163-4/Zhou $8425 \mathrm{~B}$ and $838 \mathrm{~F}_{2}$ plants from Guizhou 98-18/Zhou $8425 \mathrm{~B}$ were highly resistant to THTT (IT $0 ;-1$ ), the maximum recombination between each of two genes and $\mathrm{LrZH} 84$ was estimated as 0.0036 at $P=0.05(10)$, indicating that $\mathrm{LrXi}$, $L r G 98$, and $L r Z H 84$ were likely to be allelic or closely linked.

Resistance genes in Zhoumai 11, Xinong 1163-4, and Zhou 8425B. In seedling tests with pathotype THTT, $145 \mathrm{~F}_{2}$ plants from Zhoumai 11/Chinese Spring segregated in 137 with IT 0; to 2 (resistant) and 8 with IT 3 to 4 (susceptible) $\left(\chi_{15: 1}^{2}=0.133,1 \mathrm{df}\right.$, $P>0.5)$, indicating two dominant resistance genes in Zhoumai

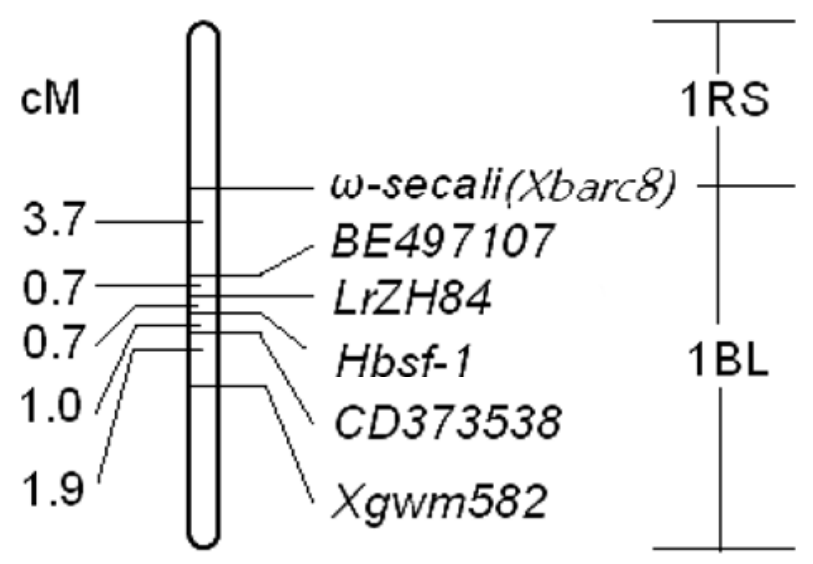

Fig. 3. Linkage map of resistance gene LrZH84 constructed with sequencetagged site markers (Hbsf-1 and $\omega$-secali), two expressed sequence tag markers (BE497107 and CD373538), and two simple sequence repeat makers (Xbarc8 and Xgwm582) on chromosome 1B using the computer program Mapmaker version 3.0. Locus names are indicated on the right side and Kosambi map distances are shown on the left side of the linkage map.
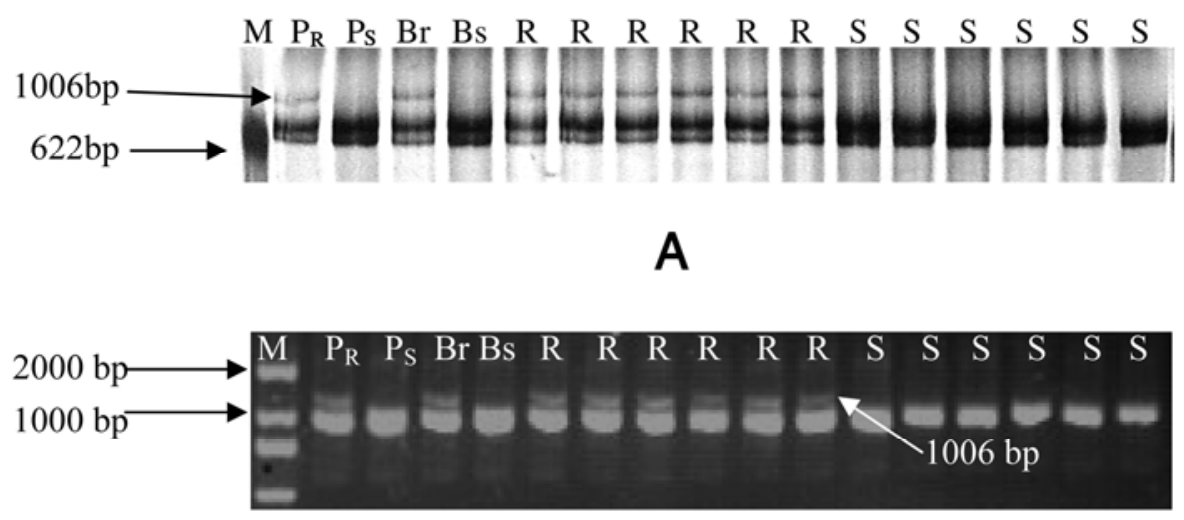

B

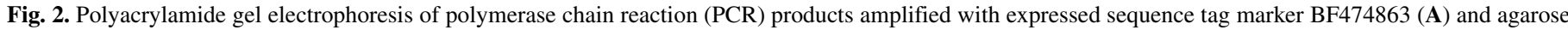

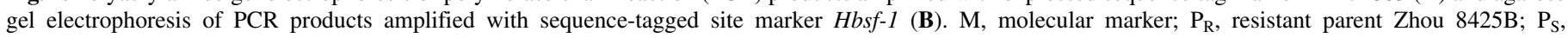
susceptible parent Chinese Spring; Br, resistant bulk; Bs, susceptible bulk; R, resistant $\mathrm{F}_{2}$ plants; and $\mathrm{S}$, susceptible $\mathrm{F}_{2}$ plants 
11. Because Zhoumai 11 was developed from the cross Zhou $8425 \mathrm{~B} / Y u m a i 17$ and was resistant to all pathotypes avirulent to Zhou 8425B $(16,33)$, we hypothesized that one of the two genes in Zhoumai 11 was LrZH84, and the other was from Yumai 17. Two markers (Xgwm582, $\omega$-secalin/Glu-B3) closely linked with LrZH84 were therefore used to test the 8 susceptible plants. All susceptible plants contained Chinese Spring alleles, indicating that one resistance gene in Zhoumai 11 was likely to be $\mathrm{LrZH84}$. In another seedling test, Zhou $8425 \mathrm{~B}$ and $285 \mathrm{~F}_{2}$ plants from Zhoumai 11/Chinese Spring were inoculated with pathotype FHTT. Zhoumai 11 was resistant (IT 2), whereas Zhou 8425B and Chinese Spring were susceptible (IT 4). The $\mathrm{F}_{2}$ population segregated monogenically, i.e., 220 plants with IT 0 ; to 2 (resistant) and 65 plants with IT 3 to 4 (susceptible) $\left(\chi_{3: 1}^{2}=0.73,1 \mathrm{df}, P>\right.$ 0.25). Two markers (Xgwm582, $\omega$-secalin/Glu-B3) closely linked with $\mathrm{LrZH} 84$ were used to test all the $\mathrm{F}_{2}$ plants, and the data showed that the gene was located at a different locus relative to LrZH84. It was therefore concluded that $\mathrm{LrZH84}$ was susceptible to pathotype FHTT and that Zhoumai 11 carried a different unknown resistance gene. A total of $232 \mathrm{~F}_{2}$ plants from Xinong 1163-4/Thatcher were inoculated with pathotype FHTT. Xinong 1163-4 was resistant (IT 1), whereas Thatcher was susceptible (IT 4), and the $\mathrm{F}_{2}$ population segregated 172 plants with IT 0 to 2 and 60 with IT 3 to 4 , indicating a single gene segregation $\left(\chi_{3: 1}^{2}=\right.$ $0.09,1 \mathrm{df}, P>0.75)$. Markers Xgwm582 and $\omega$-secalin/Glu-B3 were used to test all $\mathrm{F}_{2}$ plants of Xinong 1163-4/Thatcher, and the data showed that the gene was linked to the markers and likely to be $L r X i$. Based on these data it was evident that $L r X i$ was different from $\mathrm{LrZH} 84$.

\section{DISCUSSION}

Developing STS markers from EST markers. Qi et al. (21) mapped 16,000 EST loci into chromosome bins by Southern hybridization using wheat aneuploid and deletion stocks. The chromosome bin map of ESTs is a unique resource for SNP analysis, comparative mapping, and structural and functional analyses, as well as providing a strong tool for constructing a high density genetic maps for gene cloning. Using EST and SSR markers, Li et al. (14) and Hua et al. (13) located powdery mildew resistance genes $P m 41$ and $P m 42$, respectively. In the present study, three EST markers were closely linked to $\mathrm{LrZH84}$, and the two flanking markers Hbsf- 1 and BE497107 were closely linked to $\mathrm{LrZH84}$ with genetic distances of $0.7 \mathrm{cM}$. They are more closely linked to LrZH84 than markers Xgwm582 and Xbarc8 reported in our previous study (33).

Based on comparative genomics and collinear relationships among different genomes of graminaceous plants, resistance genes can be finely mapped using EST markers. Draper et al. (6) reported genetic relationships indicating that wheat is more closely related to Brachypodium distachyon than to rice. Using the combination of $B$. distachyon genome sequence (26) and wheat EST sequence information we should be able to find more closely linked or even co-segregating markers for map-based cloning.

Although the EST technique is an effective method for identifying molecular markers for disease resistance genes, its use in MAS may be limited for two reasons. Firstly, EST primers produce many monomorphic bands in addition to targeted polymorphisms and these may confound scoring. Secondly, analysis of PCR products amplified with EST primers using nondenaturing polyacrylamide gel electrophoresis and silver staining is too complicated. Hence it is better to convert EST markers into sequence-specific PCR-based STS markers, which are easier to use and to combine with other markers across a wide range of genotypes.

In this study, the EST marker locus, BF474863, closely linked to LrZH84 was converted into a useful STS marker. The STS marker was used to test 40 NILs and 38 descendants of Zhou $8425 \mathrm{~B}$, only one resistant line derived from Zhou 8425B did not carry the STS marker Hbsf-1 and 1BL.1RS translocation, indicating that the line could be a recombinant. These results indicated that $H b s f-1$ was effective for detecting $L r Z H 84$ in wheat lines derived from Zhou 8425B. In another test (data not shown) one resistant line (5R616) and four susceptible lines (LB 0458, Xinmai 9, Yannong 9, and 96-22-2-3) carried Hbsf-1 but did not have the 1BL.1RS translocation, and three susceptible lines (Xinmai 208, Lantian 9, and Mian 2000-36) carried 1BL.1RS but not $H b s f-1$, indicating the marker must be located in chromosome 1BL rather than being derived from rye and that $H b s f-1$ cannot specifically detect LrZH84. Xinong 1163-4 and Guizhou 98-18 carry the resistance genes $\operatorname{LrXi}$ and $L r G 98$, respectively. The flanking markers linked to these two genes are same as those for LrZH84 and no susceptible plants were found in allelism tests $(4,15,33)$, indicating that $L r X i$ and $L r G 98$ were likely to be allelic or closely linked to LrZH84 because they produce different infection types with some $P$. triticina pathotypes. Xinong 1163-4 and Guizhou 98-18 also carried both $H b s f-1$ and 1BL.1RS, indicating that $H b s f-1$ could also be used in detecting alleles of $L r Z H 84$.

Distribution of $\mathrm{LrZH84}$ in Chinese wheat lines. Since the early 1970s, wheat cultivars with the 1BL.1RS translocation carrying Lr26, derived from Lovrin 13, Predgornaia 2, Kavkaz, and Neuzucht, were widely used in Chinese breeding programs (11). Of these, Predgornaia 2 is resistant to pathotype THTT, which is avirulent to LrZH84, but Lovrin 13 and Kavkaz are susceptible, indicating that Lovrin 13 and Kavkaz do not carry LrZH84 (33). A total of 44 cultivars with $\operatorname{Lr} 26$ were identified among a set of 102 Chinese wheats, but only 10 of them were resistant to THTT (16). Based on gene postulation, genetic analyses, allelism tests and SSR marker tests, Bimai 16 (31), Tian 95HF2 (34) and Zhoumai 11 have $L r Z H 84$, whereas Guizhou 9818 (4) and Xinong 1163-4 (15) have an allele or a closely linked gene with $L r Z H 84$. LrZH84 in Zhoumai 11 came from Zhou 8425B but the gene in Bimai 16 and Tian 95HF2 could not be traced to Predgornaia 2 because the pedigrees of these two lines are very complicated $(31,34)$.

Resistance genes in Zhoumai 11, Guizhou 98-18, and Xinong 1163-4. Based on the seedling tests with FHTT, Zhoumai 11 has a resistance gene differed from $\mathrm{LrZH84}$. In seedling tests of Guizhou 98-18, Xinong 1163-4 and Zhou 8425B with pathotype TCGT, Guizhou 98-18 and Xinong 1163-4 were resistant, whereas Zhou $8425 \mathrm{~B}$ was susceptible. The $\mathrm{F}_{2}$ populations from Guizhou 98-18/Zhou 8425B and Xinong 1163-4/Zhou 8425B tested with pathotype TCGT each segregated for a single dominant resistance gene (data not shown). Marker analyses indicated that neither resistance gene was on 1BL; thus, there must be other resistance genes in Guizhou 98-18 and Xinong 1163-4.

\section{ACKNOWLEDGMENTS}

We thank R. A. McIntosh for critical review of this manuscript, Plant Breeding Institute, University of Sydney, Australia. The project was supported by the National Natural Science Foundation of China (30971772 and 30700505) and Postdoctoral Science Foundation of China (2011M500672).

\section{LITERATURE CITED}

1. Adams, M. D., Kelley, J. M., Gocayne, J. D., Dubnick, M., Polymeropoulos, M. H., Xiao, H., Merril, C. R., Wu, A., Olde, B., Moreno, R. F., Kerlavage, A. R., McCombie, W. R., and Venter, J. C. 1991. Complementary DNA sequencing: Expressed sequence tags and human genome project. Science 252:1651-1656.

2. Bassam, B. J., Caetano-Anolles, G., and Gresshoff, P. M. 1991. Fast and sensitive silver staining of DNA in polyacrylamide gels. Anal. Biochem. 196:80-83.

3. Chai, J. F., Zhou, R. H., Jia, J. Z., and Liu, X. 2006. Development and application of a new co-dominant PCR marker for detecting 1BL.1RS 
wheat-rye chromosome translocations. Plant Breed. 125:302-304

4. Chen, X. C., Li, X., Li, Z. F., Chen, H., Gao, M., and Liu, D. Q. 2010. Molecular mapping of leaf rust resistance gene $\operatorname{LrG98}$ in Chinese wheat line Guizhou 98-18. Acta Phytopathol. Sin. 40:489-494.

5. De Froidmont, D. 1998. A co-dominant marker for the 1BL/1RS wheatrye translocation via multiplex PCR. J. Cereal Sci. 27:229-232.

6. Draper, J., Mur, L. A. J., Jenkins, G., Ghosh-Biswas, G. C., Bablak, P., Hasterok, R., and Routledge, A. P. M. 2001. Brachypodium distachyon: A new model system for functional genomics in grasses. Plant Physiol. 127:1539-1555.

7. Dyck, P. L., Kerber, E. R., and Lukow, O. M. 1987. Chromosome location and linkage of a new gene (Lr33) for reaction to Puccinia recondita in common wheat. Genome 29:463-466.

8. Dyck, P. L., and Sykes, E. E. 1994 Genetics of leaf-rust resistance in three spelt wheats. Can. J. Plant Sci. 74:231-233.

9. Grodzicker, T., Williams, J., Sharp, P., and Sambrook, J. 1974. Physical mapping of temperature sensitive mutations of adenovirus. Quant. Biol. 39:439-446.

10. Hanson, W. D. 1959. Minimum family sizes for the planning of genetic experiments. Agron. J. 51:711-715.

11. He, Z. H., Rajaram, S., Xin, Z. Y., and Zhang, G. Z. 2001. A history of wheat breeding in China. CIMMYT, Mexico, D.F.

12. Herrera-Foessel, S. A., Singh, R. P., Huerta-Espino, J., Rosewarne, G. M., Periyannan, S. K., Viccars, L., Calvo-Salazar, V., Lan, C., and Lagudah, E. S. 2012. Lr68: A new gene conferring slow rusting resistance to leaf rust in wheat. Theor. Appl. Genet. 124:1475-1486.

13. Hua, W., Liu, Z. J., Zhu, J., Xie, C. J., Yang, T. M., Zhou, Y. L., Duan, X. Y., Sun, Q. X., and Liu, Z. Y. 2009. Identification and genetic mapping of Pm42, a new recessive wheat powdery mildew resistance gene derived from wild emmer (Triticum turgidum var. dicoccoides). Theor. Appl. Genet. 119:223-230.

14. Li, G. Q., Fang, T. L., Zhang, H. T., Xie, C. J., Li, H. J., Yang, T. M., Nevo, E., Fahima, T., Sun, Q. X., Liu, Z. Y. 2009. Molecular identification of a new powdery mildew resistance gene Pm41 on chromosome 3BL derived from wild emmer (Triticum turgidum var. dicoccoides). Theor. Appl. Genet. 119:531-539.

15. Li, X., Li, Z. F., Li, Y. N., Zhao, Z. Q., Liu, D. Q., Wang, C. F., Gao, L. J., and Sun, D. J. 2010. Genetic analysis and molecular mapping of leaf rust resistance gene in wheat line Xinong 1163-4. Sci. Agric. Sin. 43:23972402.

16. Li, Z. F., Xia, X. C., He, Z. H., Li, X., Zhang, L. J., Wang, H. Y., Meng, Q. F., Yang, W. X., Li, G. Q., and Liu, D. Q. 2010. Seedling and slow rusting resistance to leaf rust in Chinese wheat cultivars. Plant Dis. 94:45-53.

17. Lincoln, S., Daly, M., and Lander, E. 1992. Constructing Genetic Maps with Mapmaker/EXP3.0. Whitehead Institute Technical Report, 3rd ed. Whitehead Institute, Cambridge, MA.

18. McIntosh, R. A., Dubcovsky, J., Rogers, W. J., Morris, C. F., Appels, R., and Xia, X. C. 2011. Catalogue of gene symbols for wheat: 2011 supplement. Ann. Wheat News Lett. 57:314-315.

19. Michelmore, R. W., Paran, I., and Kesseli, R. V. 1991. Identification of markers linked to disease-resistance genes by bulked segregant analysis: A rapid method to detect markers in specific genomic regions by using segregating populations. Proc. Natl. Acad. Sci. USA 88:9828-9832.

20. Morgante, M., and Olivieri, A. M. 1993. PCR-amplified microsatellite as markers in plant genetics. Plant J. 3:175-182.

21. Qi, L. L., Echalier, B., Chao, S., Lazo, G. R. Butler, G. E., Anderson, O.
D., Akhunov, E. D., Dvořák, J., Linkiewicz, A. M., Ratnasiri, A. Dubcovsky, J., Bermudez-Kandianis, C. E., Greene, R. A., Kantety, R., LaRota, C. M., Munkvold, J. D., Sorrells, S. F., Sorrells, M. E., Dilbirligi, M., Sidhu, D., Erayman, M., Randhawa, H. S., Sandhu, D., Bondareva, S. N., Gill, K. S., Mahmoud, A. A., Ma, X. F., Miftahudin, Gustafson, J. P., Conley, E. J., Nduati, V., Gonzalez-Hernandez, J. L., Anderson, J. A., Peng, J. H., Lapitan, N. L. V., Hossain, K. G., Kalavacharla, V., Kianian, S. F., Pathan, M. S., Zhang, D. S., Nguyen, H. T., Choi, D. W., Fenton, R. D., Close, T. J., McGuire, P. E., Qualset, C. O., and Gill, B. S. 2004. A chromosome bin map of 16,000 expressed sequence tag loci and distribution of genes among the three genomes of polyploid wheat. Genetics 168:701-712.

22. Roelfs, A. P., Singh, R. P., and Saari, E. E. 1992. Rust Diseases of Wheat: Concepts and Methods of Disease Management. CIMMYT, Mexico.

23. Rosewarne, G. M., Singh, R. P., Huerta-Espino, J., William, H. M., Bouchet, S., Cloutier, S., McFadden, H., and Lagudah, E. S. 2006. Leaf tip necrosis, molecular markers and b1-proteasome subunits associated with the slow rusting resistance genes Lr46/Yr29. Theor. Appl. Genet. 112:500-508.

24. Sharp, P. J., Kreis, M., Shewry, P. R., and Gale, M. D. 1988. Location of $\beta$-amylase sequence in wheat and its relatives. Theor. Appl. Genet. 75:286-290.

25. Singh, R. P., Mujeeb-Kazi, A., and Huerta-Espino, J. 1998. Lr46: A gene conferring slow-rusting resistance to leaf rust in wheat. Phytopathology 88:890-894.

26. Vogel, J. P., Garvin, D. F., Mockler, T. C., and Schmutz, J. 2010. Genome sequencing and analysis of the model grass Brachypodium distachyon. Nature 463:763-768.

27. Vos, P., Hogers, R., Bleeker, M., Reijans, M. van de Lee, T., Hornes, M., Frijters, A., Pot, J., Peleman, J., Kuiper, M., and Zabeau, M. 1995. AFLP: A new technique for DNA fingerprinting. Nucleic Acids Res. 23:44074414.

28. Williams, J. G. K., Kubelik, A. R., Livak, K. J., Rafalski, J. A., and Tingey, S. V. 1990. DNA polymorphisms amplified by arbitrary primers are useful as genetic markers. Nucleic Acids Res. 18:6531-6535.

29. Xu, M. L., Huaracha, E., and Korban, S. S. 2001. Development of sequence-characterized amplified regions (SCARs) from amplified fragment length polymorphism (AFLP) markers tightly linked to the Vf gene in apple. Genome 44:63-70.

30. Yin, G. H., Wang, J. W., Wen, W. E., He, Z. H., Li, Z. F., Wang, H., and Xia, X. C. 2009. Mapping of wheat stripe rust resistance gene $\mathrm{YrZH} 84$ with RGAP markers and its application. Acta Agron. Sin. 35:1274-1281.

31. Zhang, H., Xia, X. C., He, Z. H., Li, X., Li, Z. F., and Liu, D. Q. 2011. Molecular mapping of leaf rust resistance gene LrBil6 in Chinese wheat cultivar Bimai 16. Mol. Breed. 28:527-534.

32. Zhang, X. K., Liu, L., He, Z. H., Sun, D. J., He, X. Y., Xu, Z. H., Zhang, P. P., Chen, F., and Xia, X. C. 2008 Development of two multiplex PCR assays targeting improvement of bread-making and noodle qualities in common wheat. Plant Breed. 127:109-115.

33. Zhao, X. L., Zheng, T. C., Xia, X. C., He, Z. H., Liu, D. Q., Yang, W. X., Yin, G. H., and Li, Z. F. 2008. Molecular mapping of leaf rust resistance gene $\mathrm{LrZH} 84$ in Chinese wheat line Zhou 8425B. Theor. Appl. Genet. 117:1069-1075

34. Zhou, Y., Li, X., Wang, L., Zhang, Y., Li, Z. F., and Liu, D. Q. 2010. Molecular mapping of leaf rust resistance genes in wheat line Tian 95HF2. Acta Agron. Sin. 36:1265-1269. 